\title{
Ankle-brachial index and subclinical atherosclerosis in type 1 diabetes
}

\author{
Alexandra Corrêa Gervazoni Balbuena de Lima1* (1), Mariana Fiuza Gonçalves² (1), \\ Ester Vasconcelos Rocha² (10, Luciana Bartolmei Orru D'Ávila1 ${ }^{\mathbb{D}}$, André Neves Mascarenhas ${ }^{1,2}$
}

\section{SUMMARY}

OBJECTIVE: To assess the prevalence of altered ankle-brachial index $(<0.9$ or $>1.3)$ in patients with type 1 diabetes and to compare it with the presence of subclinical atherosclerosis by carotid ultrasound.

METHODS: Prospective, cross-sectional study in which 45 adults with type 1 diabetes were evaluated (age $34 \pm 10$ years, $46.7 \%$ men). The data collected included anamnesis, clinical evaluation, calculation of the ankle-brachial index (relationship between systolic blood pressure in the ankle and brachial artery), and performance of carotid ultrasound.

RESULTS: Thirty-two patients had ankle-brachial index $>1.3$ (66.7\%) and no patient had ankle-brachial index $<0.9$. Carotid echocardiography was performed on 21 patients, 4 (19\%) of whom had atherosclerosis. Age $>35$ years and ankle-brachial index $>1.4$ showed a good correlation with atherosclerosis $(r=0.49, p=0.021 ; r=0.56, p=0.008$, respectively). A model associating age $>35$ years and ankle-brachial index $>1.4$ showed an excellent relationship with atherosclerosis $(r=0.59, p=0.004)$.

CONCLUSIONS: Our study showed that vascular calcification (ankle-brachial index $>1.4$ ) was frequent in this population with type 1 diabetes and associated with subclinical atherosclerosis. A model combining ankle-brachial index $>1.4$ and age $>35$ years showed an excellent correlation with atherosclerosis and can assist in clinical suspicion and optimize the request for additional tests.

KEYWORDS: Vascular calcification. Ankle-brachial index. Diabetes mellitus, type 1. Atherosclerosis.

\section{INTRODUCTION}

Type 1 Diabetes (T1D) is the most common endocrinopathy in childhood and adolescence; global statistics estimate that 382 million people live with T1D and that number tends to reach 592 million in $2035 .{ }^{1}$ The risk of cardiovascular events and neurological complications is approximately four times higher among diabetics compared to non-diabetics. ${ }^{2}$ Atherosclerotic cardiovascular disease, especially coronary artery disease, is the main cause of mortality and morbidity in diabetes. Furthermore, T1D patients have more vascular calcification $(\mathrm{VC})$ compared to non-diabetics, and the presence of calcification is related to extensive and accelerated atherosclerosis in these individuals. ${ }^{3}$

The Ankle Brachial Index (ABI) is normally used for monitoring atherosclerotic disease of lower limbs and reflects the reduction of systemic arterial pressure in the lower limb, as a consequence of proximal atherosclerotic obstruction. The ABI can be also used to estimate the progression and severity of

\footnotetext{
${ }^{1}$ Hospital Regional da Asa Norte, Secretaria de Saúde do Distrito Federal - Brasília, (DF), Brazil.

${ }^{2}$ Escola de Ciências da Saúde - Brasília, (DF), Brazil.

*Corresponding author: alexandra.lima@gmail.com

Conflicts of interest: the authors declare there are no conflicts of interest. Funding: The medical student Mariana Fiuza Gonçalves received a scholarship from the Scientific Initiation Program of the School of Health Science (Escola Superior de Ciências da Saúde) - Brasilia/DF. Received on August 30, 2020. Accepted on September 07, 2020.
} 
systemic atherosclerosis. ${ }^{2}$ Abnormal levels $(\mathrm{ABI}<0.9$ and $>1.3$ ) are associated with the risk of cardiovascular events, in addition to the higher prevalence of atherosclerotic plaque. ${ }^{4}$

T1D is associated with an elevated incidence of atherosclerotic disease and mortality. ${ }^{5}$ Based on this, the early identification of subclinical atherosclerosis is essential to prevent cardiovascular disease in these patients. Then, the purpose of this study was to assess the occurrence of subclinical atherosclerosis in asymptomatic T1D adults. For this purpose, subclinical atherosclerosis was assessed by $\mathrm{ABI}$ and confirmed with carotid ultrasound.

\section{METHODS}

Prospective, cross-sectional study in T1D patients, followed up at the Endocrinology Outpatient Clinic of the Specialized Center for Diabetes, Obesity and Arterial Hypertension of the Central Health Region of the State Health Department in Brasília - Federal District - Brazil, from February to June 2020.

Anamnesis was performed, including evaluation of previous acute myocardial infarction (MI), stroke and peripheral arterial disease; time since diagnosis of the diabetes, presence of comorbidities - dyslipidemia, systemic arterial hypertension, smoking, family history of early coronary artery disease, sedentary lifestyle (which, according to the World Health Organization, is lower than 150 minutes of moderate intensity activity, less than 3 times a week) and continuous use of medications.

Clinical evaluation was performed with anthropometric measurements (weight $(\mathrm{kg})$, height $(\mathrm{cm})$, body mass index (BMI, $\left.\mathrm{kg} / \mathrm{m}^{-2}\right)$ ) and physical examination. In addition, medical records were reviewed to assess laboratory tests (blood glucose (mg/ $\left.\mathrm{dL}^{-1}\right)$, total cholesterol $\left(\mathrm{mg} / \mathrm{dL}^{-1}\right)$, LDL-cholesterol $\left(\mathrm{mg} / \mathrm{dL}^{-1}\right)$, HDL-cholesterol $\left(\mathrm{mg} / \mathrm{dL}^{-1}\right)$, triglycerides $\left(\mathrm{mg} / \mathrm{dL}^{-1}\right)$ and glycated hemoglobin (\%) when available up to 6 months from the date of clinical evaluation.

To calculate the ABI, the patient remained relaxed, in the supine position. The measurement of the systolic blood pressure (SBP) was performed in the posterior tibial arteries and in the brachial arteries of each limb. The SBP measurement was performed three times on each limb, with universal cuff, using automatic blood pressure monitor (OMRON, HEM 7130, Omron Health Care Brazil, São Paulo, Brazil). The ABI was obtained by simply dividing the largest SBP obtained in each artery of the lower limb by the upper limb. The ABI was considered abnormal, $<0.9$ (indicative of peripheral atherosclerosis) or $>1.3$ (indicative of vascular calcification). ${ }^{6}$ The patients were advised to avoid caffeine intake, tobacco use or physical exercise in the last four hours before evaluation.
Subsequently, patients underwent evaluation of atherosclerosis by Doppler ultrasound, performed by a single experienced echocardiographer, without knowing the clinical and laboratory data of the study subjects. The images were obtained using a vascular ultrasound (Vivid S6 and Vivid S60 GE Medical Systems, GE Healthcare do Brasil, São Paulo, Brazil) equipped with a 7.5-10 MHz linear matrix transducer. Atherosclerosis was defined as the increase in IMT above $1.5 \mathrm{~mm}$, or the presence of carotid plaque, both detected by vascular ultrasonography. ${ }^{7}$

The IMT was characterized by the presence, in a two-dimensional mode, of a double line with the definition of the light-intimate and medium-adventitia interfaces. The distance between the two acoustic interfaces was considered the measure of the IMT. The IMT measurement was automatically obtained on the posterior wall of the common carotids on the right and on the left, at least $1 \mathrm{~cm}$ proximal to the flow divider - referred to as bifurcation. The atheromatous carotid plaque was defined as a focal structure extending across at least $0.5 \mathrm{~mm}$ for vessel light, and/or measuring more than $50 \%$ of the value of the adjacent IMT measurement, and/or an IMT measurement greater than $1.5 \mathrm{~mm} .^{7}$

\section{Sample}

The research subjects should meet the criteria of having T1D and age over 18 years. Seventy-five patients with diabetes were evaluated and 45 T1D (21 men and 24 women) were included in the study. The study excluded patients with type 2 diabetes, patients with clinical manifestations of coronary artery disease (MI and stable angina), cardiovascular disease (stroke and transient ischemic attack), peripheral obstructive arterial disease (claudication), patients with aortic aneurysm and/or heart failure and those who did not consent to participate by signing the Free and Informed Consent Form.

The research was approved by the Research Ethics Committee of Health Science Teaching and Research Foundation of the Federal District (CAE no 17592619.9.0000.5553), guaranteeing confidentiality to the participants' information, according to Resolution 196/96 of the National Health Council, despite the research involving human beings.

\section{Statistical analysis}

The statistical analysis was performed using a statistical program (SPSS 24.0, SPSS, IBM, Armonk, NY). We categorized patients according to the presence or absence of atherosclerosis on the carotid ultrasound, and the $\mathrm{ABI}$ value $<0.9$, between 0.9 and 1.3 and $>1.3$. Quantitative variables were described as mean \pm standard deviation, and categorical variables were described in absolute numbers. Student's independent t-test and Chi-square test were used to assess the differences between 
the groups. Laboratory tests were not included in the statistical analysis due to the small number of tests, which could lead to a bias in the analysis, but the data are shown in Table 1 .

Spearman's non-parametric correlation was used to assess the correlation of factors - age, time since diagnosis and ABI with atherosclerosis. The Receiver Operating Characteristic Curve (ROC) was used to assess the sensitivity and specificity, for different cutoff points of the variables associated with atherosclerosis (age and ABI). Spearman's correlation was performed to assess the association of cutoff points (age $>35$ years and $\mathrm{ABI}>1.4$ ) with atherosclerosis. A model associating age $>35$ years and ITB $>1.4$ was suggested and, to validate the robustness of the model, a Spearman's correlation, the area under the ROC curve analysis (AUC) and a scatterplot were performed. All $\mathrm{p}$ values presented will be of the bilateral type, $\mathrm{p}<0.05$ and $0.05 \leq \mathrm{p} \leq 0.10$ will be considered significant and marginally significant, respectively.

\section{RESULTS}

The 45 T1D individuals included in the study (53.3\% women) had a mean age of $34.37 \pm 10.26$ years and time of diagnosis of $16.97 \pm 8.13$ years. The prevalence of hypertension was $20 \%$, dyslipidemia $8.9 \%$, smoking $6.7 \%$ and physical inactivity $28.9 \%$. The BMI was an average of $24.57 \pm 4.38 \mathrm{~kg} . \mathrm{cm}^{-2}$. No patient had an $\mathrm{ABI}<0.9$, while $71.1 \%$ (32 patients) had an $\mathrm{ABI}>1.3$, as described in Table 1. Carotid ultrassound was performed on 21 patients, showing atherosclerosis in 4 patients (19\% of the sample), with an equal frequency between the sexes. The mean age and time since diagnosis was higher in the atherosclerosis group (Table 1).

Table 1. Clinical and Epidemiological Characteristics of Patients with Type 1 Diabetes with and without evidence of atherosclerosis on the carotid ultrasound and with an Ankle Brachial Index (ABI) of less than 0.9, between 0.9 and 1.3 and above 1.3.

\begin{tabular}{|c|c|c|c|c|c|}
\hline & \multicolumn{2}{|c|}{$\begin{array}{l}\text { Atherosclerosis } \\
(n=21)\end{array}$} & \multicolumn{3}{|c|}{$\begin{array}{l}\text { Ankle Brachial Index } \\
(n=45)\end{array}$} \\
\hline & $\begin{array}{l}\text { Present } \\
(n=4)\end{array}$ & $\begin{array}{l}\text { Absent } \\
(n=17)\end{array}$ & $\begin{array}{l}<0.9 \\
(\mathrm{n}=0)\end{array}$ & $\begin{array}{l}0.9-1.3 \\
(n=13)\end{array}$ & $\begin{array}{c}>1.3 \\
(n=32)\end{array}$ \\
\hline Age (years) & $44.7 \pm 13.5^{*}$ & $30.4 \pm 6.4^{*}$ & - & $35.2 \pm 10.6$ & $32.3 \pm 9.3$ \\
\hline Feminine gender & 2 & 9 & - & 9 & 15 \\
\hline BMI $\left(\mathrm{kg} / \mathrm{m}^{-2}\right)$ & $23.0 \pm 5.8$ & $24.8 \pm 4.6$ & - & $25.0 \pm 5.5$ & $24.3 \pm 3.86$ \\
\hline Diagnostic time (years) & $23.5 \pm 8.2^{*}$ & $15.7 \pm 8.7^{*}$ & - & $16.9 \pm 7.5$ & $17.0 \pm 8.4$ \\
\hline Hypertension & 1 & 2 & - & 5 & 4 \\
\hline Dyslipidemia & 0 & 2 & - & 1 & 3 \\
\hline Smoking & 4 & 17 & - & 1 & 2 \\
\hline Sedentary lifestyle & 2 & 5 & - & 4 & 9 \\
\hline$A B I L L$ & $1.48 \pm 0.04^{*}$ & $1.31 \pm 0.22^{*}$ & - & $1.11 \pm 0.11^{*}$ & $1.52 \pm 0.22 *$ \\
\hline$A B \mid R L$ & $1.37 \pm 0.10$ & $1.30 \pm 0.21$ & - & $1.11 \pm 0.14^{*}$ & $1.47 \pm 0.20 *$ \\
\hline Abdominal Circumference $(\mathrm{cm})$ & $73.5 \pm 10.6$ & $77.5 \pm 4.9$ & - & $81 \pm 9.2$ & $78.1 \pm 10.0$ \\
\hline Fasting glucose $\left(\mathrm{mg} / \mathrm{dL}^{-1}\right)$ & $\begin{array}{c}178 \pm 5.6 \\
(n=2)\end{array}$ & $\begin{array}{c}178.3 \pm 58 \\
(n=10)\end{array}$ & - & $\begin{array}{c}158.8 \pm 12.3 \\
(n=7)\end{array}$ & $\begin{array}{c}173.5 \pm 49.6 \\
(n=19)\end{array}$ \\
\hline Glycosylated hemoglobin (\%) & $\begin{array}{c}7.47 \pm 0.7 \\
(n=3)\end{array}$ & $\begin{array}{c}8.25 \pm 1.9 \\
(n=15)\end{array}$ & - & $\begin{array}{c}7.81 \pm 1.6 \\
(n=8)\end{array}$ & $\begin{array}{c}7.97 \pm 1.6 \\
(n=24)\end{array}$ \\
\hline $\begin{array}{l}\text { Total cholesterol } \\
\left(\mathrm{mg} / \mathrm{dL}^{-1}\right)\end{array}$ & $\begin{array}{c}167.6 \pm 36.0 \\
(n=3)\end{array}$ & $\begin{array}{c}\begin{array}{c}179.1 \pm 36.9 \\
(n=8)\end{array} \\
\end{array}$ & - & $\begin{array}{c}168.3 \pm 37.5 \\
(n=6)\end{array}$ & $\begin{array}{c}161.2 \pm 33.5 \\
(n=19)\end{array}$ \\
\hline LDL-cholesterol $\left(\mathrm{mg} / \mathrm{dL}^{-1}\right)$ & $\begin{array}{c}86.3 \pm 37.8 \\
(n=3)\end{array}$ & $\begin{array}{c}16.1 \pm 34.2 \\
(n=8)\end{array}$ & & $\begin{array}{c}96.5 \pm 33.6 \\
(n=6)\end{array}$ & $\begin{array}{c}89.3 \pm 28.3 \\
(n=19)\end{array}$ \\
\hline $\begin{array}{l}\text { HDL-cholesterol } \\
\left(\mathrm{mg} / \mathrm{dL}^{-1}\right)\end{array}$ & $\begin{array}{c}89 \pm 37.2 \\
(n=3)\end{array}$ & $\begin{array}{c}61.5 \pm 13.6 \\
(n=8)\end{array}$ & & $\begin{array}{c}56.8 \pm 14.9 \\
(n=6)\end{array}$ & $\begin{array}{c}62.1 \pm 21.1 \\
(n=19)\end{array}$ \\
\hline Triglycerides $\left(\mathrm{mg} / \mathrm{dL}^{-1}\right)$ & $\begin{array}{l}61 \pm 7.0 \\
(n=2)\end{array}$ & $\begin{array}{c}62.5 \pm 24.2 \\
(n=7)\end{array}$ & - & $\begin{array}{l}61 \pm 8.0 \\
(n=4)\end{array}$ & $\begin{array}{c}76,3 \pm 35.2 \\
(n=18)\end{array}$ \\
\hline
\end{tabular}

ABI LL: ankle brachial index in the left limbs; ABI RL: ankle brachial index in the right limbs. *Student's test, $p<0.05$. 
The univariate analysis of risk factors associated with atherosclerosis was positively correlated with age $(r=0.43, p=0.05)$ (Figure 1), with a tendency to be associated with the ABI $(\mathrm{r}=0.41, \mathrm{p}=0.07)$ (Figure 2), and there was no association with the time of diagnosis $(\mathrm{r}=0.33, \mathrm{p}=0.14)$.

All patients who had atherosclerosis showed an $\mathrm{ABI}>1.3$ $(100 \%)$. Age $>35$ years and $A B I>1.4$ were the points with the best sensitivity and specificity for the presence of carotid atherosclerosis (Table 2). In the univariate analysis, age $>35$ years and $\mathrm{ABI}>1.4$ showed an excellent correlation with atherosclerosis $(\mathrm{r}=0.499, \mathrm{p}=0.021 ; \mathrm{r}=0.56, \mathrm{p}=0.008$, respectively) (Figures 1

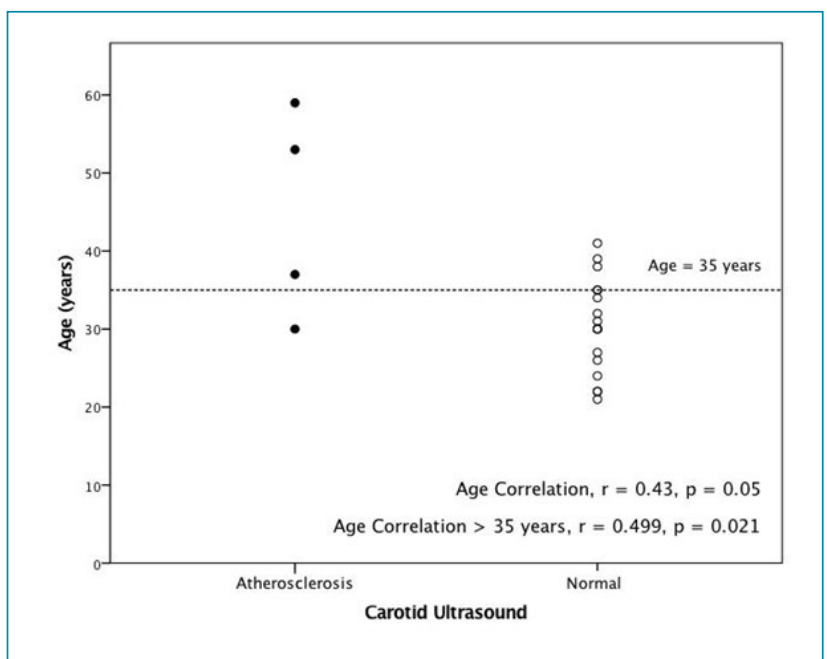

Figure 1. Scatter Plot graph of correlation between age and atherosclerosis in type 1 diabetic individuals with and without atherosclerosis by carotid ultrasound.

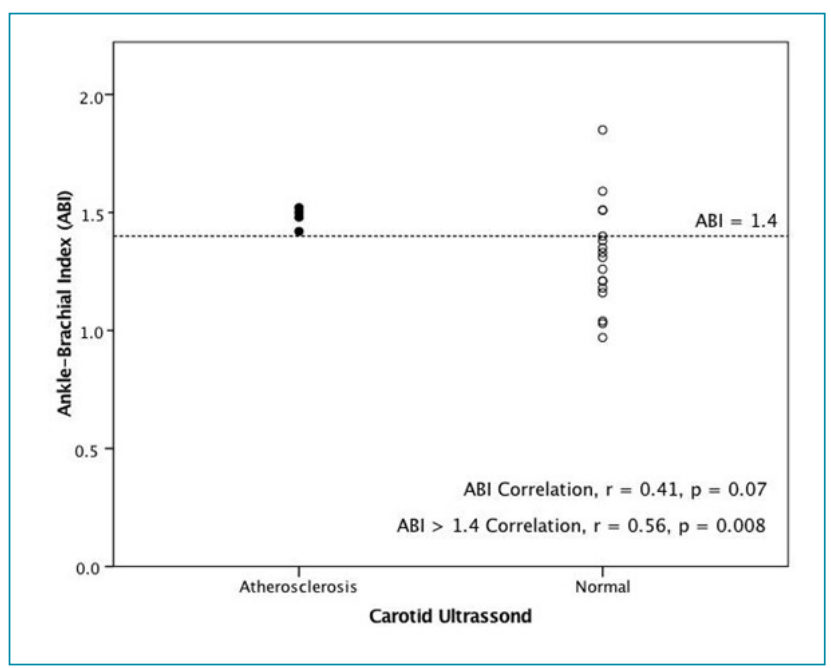

Figure 2. Scatter Plot graph of correlation between ankle brachial index $(A B I)$ and atherosclerosis in type 1 diabetic individuals with and without atherosclerosis by carotid ultrasound. and 2). In sequence, a model associating age $>35$ years and ABI >1.4 ( $r=0.599, \mathrm{p}=0.004$; AUC=0.897, $\mathrm{p}=0.016)$ stepped up the association with atherosclerosis. In Figure 3 , we illustrate the correlation between age $>35$ years and $\mathrm{ABI}>1.4$ and the presence of atherosclerosis.

\section{DISCUSSION}

Identifying subclinical atherosclerosis is extremely important to diagnose, treat and prevent the occurrence of cardiovascular disease (CVD) in diabetes. Our study demonstrated that a

Table 2. Evaluation of the sensitivity and specificity of different age cutoff points and ankle-brachial index in type 1 diabetic patients.

\begin{tabular}{l|c|c}
\hline Age (years) & $\begin{array}{c}\text { Sensitivity } \\
(\%)\end{array}$ & $\begin{array}{c}\text { Specificity } \\
(\%)\end{array}$ \\
\hline 30 & 75 & 59 \\
\hline 33 & 75 & 65 \\
\hline 35 & 75 & 83 \\
\hline 37 & 50 & 83 \\
\hline 40 & 50 & 99 \\
\hline Ankle-Brachial Index & $(\%)$ & $(\%)$ \\
\hline 1.32 & 100 & 53 \\
\hline 1.34 & 100 & 59 \\
\hline 1.36 & 100 & 65 \\
\hline 1.39 & 100 & 71 \\
\hline 1.41 & 100 & 77 \\
\hline
\end{tabular}

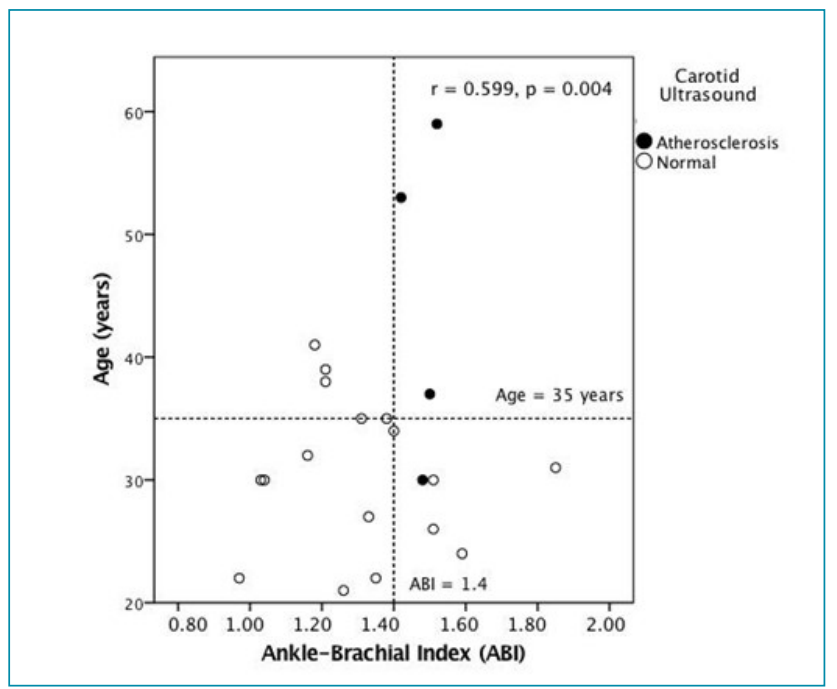

Figure 3. Scatter Plot graph of correlation between age and ankle brachial index $(A B I)$ in type 1 diabetic individuals with and without atherosclerosis by carotid ultrasound. 
simple model using age and $\mathrm{ABI}$ can estimate the risk of subclinical atherosclerosis in asymptomatic T1D patients with good accuracy, and the ABI can be a simple and low-cost tool that can assist in the screening of subclinical atherosclerosis.

Vascular calcification (VC) was quite prevalent in our population $(66.7 \%)$ and all individuals with atherosclerosis had an $\mathrm{ABI}>1.3$. There are few studies evaluating the $\mathrm{ABI}$ in T1D. In a cross-sectional study of 289 asymptomatic T1D adults, abnormal levels of $A B I$ of $<0.9$ or $>1.3$ were detected in $6 \%$ and $26 \%$, respectively. Those with abnormal ABI, $12.8 \%$, present peripheral obstructive disease and $4.8 \%$ carotid disease. ${ }^{8}$ Miller et al. explored relationships between an $\mathrm{ABI}>1.3$ and $\mathrm{VC}$ in T1D and found that an $\mathrm{ABI}>1.3$ is very likely to have VC. ${ }^{4}$ Resnick et al. showed that an ABI $>1.4$ was an independent cardiovascular risk factor. There was a U-shaped association between ABI value and cardiovascular mortality'. The increased $\mathrm{ABI}$ also reflects coronary calcifications, suggesting diffuse atheromatous disease. ${ }^{9,10}$ In our study, the $\mathrm{ABI}>1.4$ showed a good accuracy to identify carotid atherosclerosis (Figure 2).

Our study differs from others due to the absence of an $\mathrm{ABI}<0.9$, which is classically associated with atherosclerosis. ${ }^{1}$ This factor can be attributed to the low prevalence of traditional risk factors in our population - hypertension, dyslipidemia, smoking, physical inactivity and obesity.

In diabetes, the symptoms of CVD can be atypical or silent. ${ }^{1}$ The first manifestation can be sudden death, so early detection of atherosclerosis is extremely important, and this can be challenging in a young population. Although the IMT has been recognized as an early marker of atherosclerotic, this assessment is not routinely recommended for T1D young patients in clinical practice. ${ }^{11}$ In our study, the association between age and elevated ABI (Figure 3) showed good accuracy and may assist in the recommendation screening for asymptomatic T1D, in addition to reinforcing the intensive control of risk factors.

Our study had some limitations. First, due to its cross-sectional design, the number of patients who were evaluated and who performed the carotid ultrasound was reduced. In addition, laboratory tests could not be analyzed, which could lead to a better design of mechanisms associated to arterial calcification and atherosclerosis. This is an initial study and more studies with larger cohorts with a higher prevalence of subclinical atherosclerosis and longitudinal trials will be needed to elucidate the clinical risk factors associated with arterial calcification and subclinical atherosclerosis. However, our study allowed us to outline a simple assessment strategy based on the patient's age and physical examination, which can be quite cost-effective for the Public Health System.

\section{CONCLUSION}

The ABI is a simple and reliable method that has proven to be efficient in estimating subclinical atherosclerosis in T1D. Vascular calcification $(\mathrm{ABI}>1.3)$ and the $\mathrm{ABI}>1.4$ were associated with the presence of subclinical atherosclerosis in individuals with T1D. A model combination age $>35$ years and ABI $>1.4$ can be a useful and cost-effective tool to identify individuals who are most likely to have subclinical atherosclerosis and an indication to perform carotid ultrasound.

\section{ACKNOWLEDGMENT}

We are grateful to the patients who cordially contributed to this research. We thank Dr. Alexandra Rubim Camara Sete, who authorized the research project at the Specialized Center for Diabetes, Obesity and Arterial Hypertension.

\section{AUTHORS" CONTRIBUTIONS}

ACGBL: Conceptualization, Formal Analysis, Writing - Original Draft, Writing-Review \& Editing. MFG: Conceptualization, Formal Analysis, Writing - Original Draft, Writing - Review \& Editing. EVR: Conceptualization, Formal Analysis, Writing-Original Draft, Writing - Review \& Editing. LBOD: Conceptualization, Writing Original Draft, Writing-Review \& Editing. ANM: Conceptualization, Writing - Original Draft, Writing - Review \& Editing.

\section{REFERENCES}

1. Fan W. Epidemiology in diabetes mellitus and cardiovascular disease. Cardiovasc Endocrinol. 2017;6(1):8-16. https://doi. org/10.1097/XCE.0000000000000116

2. Chevtchouk L, Silva MHS, Nascimento OJM. Anklebrachial index and diabetic neuropathy: study of 225 patients. Arq Neuropsiquiatr. 2017;75(8):533-8. https://doi. org/10.1590/0004-282X20170084

3. Rodrigues TC, Canani LH, Gross JL. Síndrome metabólica, resistência à ação da insulina e doença cardiovascular no diabete melito tipo 1. Arq Bras Cardiol. 2010;94(1):134-9. https://doi.org/10.1590/S0066-782X2010000100020
4. Ix JH, Miller RG, Criqui MH, Orchard TJ. Test characteristics of the ankle-brachial index and ankle-brachial difference for medial arterial calcification on X-ray in type 1 diabetes. J Vasc Surg. 2012;56(3):721-7. https://doi.org/10.1016/j. jvs.2012.02.042

5. Kupfer R, Larrúbia MR, Bussade I, Pereira JRD, Lima GAB, Epifanio MA, et al. Predictors of subclinical atherosclerosis evaluated by carotid intima-media thickness in asymptomatic young women with type 1 diabetes mellitus. Arch Endocrinol Metab. 2017;61(2):115-21. https://doi.org/10.1590/23593997000000255 
6. Newman AB, Siscovick DS, Manolio TA, Polak J, Fried LP, Borhani $N O$, et al. Ankle-arm index as a marker of atherosclerosis in the cardiovascular health study. Cardiovascular Heart Study (CHS) Collaborative Research Group. Circulation. 1993;88(3):83745. https://doi.org/10.1161/01.cir.88.3.837

7. Freire CMV, Alcantara ML de, Santos SN dos, Amaral SI do, Veloso O, Porto CLL, et al. Recomendação para a quantificação pelo ultrassom da doença aterosclerótica das artérias carótidas e vertebrais: grupo de trabalho do departamento de imagem cardiovascular da sociedade brasileira de cardiologia - DIC SBC. Arq Bras Cardiol: Imagem Cardiovasc. 2015;28:e1-64. https://doi.org/10.5935/2318-8219.20150018

8. Nattero-Chávez L, Redondo López S, Alonso Díaz S, Garnica Ureña M, Fernández-Durán E, Escobar-Morreale HF, et al. The peripheral atherosclerotic profile in patients with type 1 diabetes warrants a thorough vascular assessment of asymptomatic patients. Diabetes Metab Res Rev. 2019;35(2):e3088. https:// doi.org/10.1002/dmrr.3088

9. Resnick HE, Lindsay RS, McDermott MMG, Devereux RB, Jones $\mathrm{KL}$, Fabsitz RR, et al. Relationship of high and low ankle brachial index to all-cause and cardiovascular disease mortality: the strong heart study. Circulation. 2004;109(6):733-9. https:// doi.org/10.1161/01.CIR.0000112642.63927.54

10. Potier L, Abi Khalil C, Mohammedi K, Roussel R. Use and utility of ankle brachial index in patients with diabetes. Eur J Vasc Endovasc Surg. 2011;41(1):110-6. https://doi.org/10.1016/j. ejvs.2010.09.020

11. American Diabetes Association. 10 - Cardiovascular disease and risk management: standards of medical care in diabetes-2019. 2019;42(Suppl 1):S103-23. https://doi.org/10.2337/dc19-S010 